\title{
The Benefits of Yoga for Individuals with Traumatic Brain Injury
}

\author{
Wesley Johnson*, John Hurt and Brad Cantley \\ Department of Physician Assistant Studies, Samford University, USA
}

Submission: July 27, 2019; Published: August 26, 2019

*Corresponding author: Wesley Johnson, Department of Physician Assistant Studies, Samford University, USA

\begin{abstract}
Traumatic brain injury affects an estimated 69 million individuals worldwide every year. The long-term effects of traumatic brain injury can lead to significant chronic medical problems such as decreased motor function, cognitive decline, decreased respiratory function, and sleep disturbances. Traumatic brain injuries also contribute to annual excess healthcare expenditures. New holistic approaches to the rehabilitation of traumatic brain injury patients have shown some promise in improving patient health and decreasing health care costs. Yoga is an intervention that may be beneficial when integrated into a rehabilitation program for this patient population. This review will examine the benefits of yoga in the rehabilitation process and its potential benefits in traumatic brain injury patients. A review of literature was conducted through the Samford University library database and found positive results in the use of yoga as part of the rehabilitation process of traumatic brain injury patients. .

Keywords: Traumatic brain injury; yoga; Rehabilitation; Non-pharmacologic treatment; Holistic care
\end{abstract}

\section{Introduction}

Traumatic brain injury (TBI) affects an estimated 69 million individuals worldwide each year [1]. The highest overall incidence of TBI is in North America and is responsible for $30 \%$ of injury deaths in the United States1. Long-term effects of TBI are broad and can lead to chronic changes in cognition, motor and sensation function, behavioral changes, respiratory function, chronic headaches, sleep disturbance and decreased emotional well-being [2,3]. The economic burden of TBI is an estimated $\$ 76.5$ billion yearly [2]. Over the past two decades the United States has also seen a rise in traumatic brain injuries among its military personnel fighting in the War on Terror. According to recent data, $33 \%$ of all combat-injured patients and $60 \%$ of blastinjured patients at Walter Reed Army National Military Medical Center had suffered a TBI [4]. Approximately 15\% of all troops in active combat in the War on Terror possibly suffered a TBI [4]. Rehabilitation for patients suffering from chronic TBI can impact both patient outcomes and the economic burden of TBI. Research has shown that implementation of a TBI rehabilitation program can increase patient levels of function and can greatly reduce the long-term cost to patients and the healthcare system [5]. Recently, the practice of yoga has been incorporated into rehabilitation programs of both military and civilian patients suffering from TBI. In an effort to better validate the usefulness of yoga in the rehabilitation of TBI patients, a review of literature was conducted to determine the effectiveness of these programs.

\section{Methods}

A literature search was conducted to identify studies focusing on the use of yoga in the rehabilitation of patients suffering from TBI. The Samford University library database was utilized, and the following search terms were used: Yoga and Traumatic Brain Injury, Yoga and Rehabilitation and Traumatic Brain Injury, Yoga and Brain Injury.

\section{Selection of Studies}

\section{Inclusion Criteria}

a. Studies were published in English

b. Published in the past 10 years

c. Studies focused specifically on the use of yoga for brain injuries

d. At least one outcome measurement tool utilized to measure participant progress

\section{Exclusion Criteria}

i. Studies were not in English

ii. Studies were older than 10 years

iii. Studies did not focus specifically on the use of yoga for brain injuries 
iv. There were no measurable outcomes reported in the studies

A total of 99 articles were found through the database search. 84 articles were excluded after review of the title and abstract.
The 15 remaining articles were then examined closely using the selection criteria and a final 6 articles were included in the final literature review.

Results

Table 1: Description of Studies.

\begin{tabular}{|c|c|c|c|c|}
\hline & Participants & Experimental & Control & Measurements \\
\hline Silverthorne et al. [3] & $\begin{array}{c}\mathrm{N}=16 ; \mathrm{n}=10 \text { yoga, } \mathrm{n}=6 \\
\text { control }\end{array}$ & $\begin{array}{l}\text { Weekly yoga sessions for } \\
40 \text { weeks }\end{array}$ & No yoga intervention & $\begin{array}{l}\text { Exhale strength, breath hold, } \\
\text { breathing rate, heart rate, physi- } \\
\text { cal function, general health }\end{array}$ \\
\hline Montgomery et al. [6] & $\mathrm{N}=3$ & $\begin{array}{c}\text { Weekly yoga sessions for } \\
8 \text { weeks }\end{array}$ & $\mathrm{N} / \mathrm{A}$ & $\begin{array}{l}\text { Difficulty in Emotion Regulation } \\
\text { Scale (DERS), Quality of Life Af- } \\
\text { ter Brain Injury Scale (QOLIBRI) }\end{array}$ \\
\hline Combs et al. [7] & $\mathrm{N}=19$ & $\begin{array}{l}\text { Weekly yoga sessions and } \\
\text { mindfulness-based stress } \\
\text { reduction program for } 32 \\
\text { weeks }\end{array}$ & $\mathrm{N} / \mathrm{A}$ & $\begin{array}{l}\text { Pain, sleep, mood/anxiety, atten- } \\
\text { tion, self-awareness }\end{array}$ \\
\hline Donnelly et al. [8] & $\begin{array}{c}\mathrm{N}=31 ; \mathrm{n}=16 \text { yoga }, \mathrm{n}=15 \\
\text { control }\end{array}$ & Weekly yoga for 8 weeks & No yoga intervention & $\begin{array}{l}\text { Quality of Life After Brain Injury } \\
\text { Scale (QOLIBRI) }\end{array}$ \\
\hline Wen et al. [9] & $\mathrm{N}=2$ & $\begin{array}{l}\text { Yoga sessions twice-a-week } \\
\text { for } 6 \text { weeks }\end{array}$ & $\mathrm{N} / \mathrm{A}$ & $\begin{array}{l}\text { Pittsburgh Sleep Quality Index, } \\
\text { Neuropathy pain scale, Behavior } \\
\text { Rating Inventory of Executive } \\
\text { Function (BRIEF), Beck Depres- } \\
\text { sion Inventory }\end{array}$ \\
\hline Schmid et al. [10] & $N=3$ & $\begin{array}{c}\text { Weekly 1:1 yoga session for } \\
8 \text { weeks }\end{array}$ & $\mathrm{N} / \mathrm{A}$ & $\begin{array}{l}\text { Balance, balance confidence, } \\
\text { pain, range of motion, strength } \\
\text { and mobility }\end{array}$ \\
\hline
\end{tabular}

All six studies measured the varying effects of yoga during the rehabilitation of patients with traumatic brain injuries (Table 1). All studies showed significant improvements in patients who used yoga as a part of their rehabilitation program. Silverthorne et al. [3] found that compared to a control group, a 40-week yoga program showed significant improvement in patients breath holding $(\mathrm{p}=<.05)$, heart rate $(\mathrm{p}=<.01)$, physical function $(\mathrm{p}=<.01)$, and self-reported emotional well-being $(\mathrm{p}=<.01)$. Montgomery et al.6 evaluated the effects of an 8-week yoga program on patients with TBI. The Difficulty in Emotional Regulation Scale (DERS) and the Quality of Life After Brain Injury (QOLIBRI) scores were used for quantitative analysis.

At the end of the study, participants had a 16\% improvement for the DERS and a 6\% improvement for the QOLIBRI [6]. Qualitative analysis of the program was also found to be beneficial in terms of self-reported concentration, self-control, confidence, and self-development [6]. Combs et al. [7] found during their pilot study of 19 military personnel with TBI in a Veterans Affairs Polytrauma Transitional Rehabilitation Program (PTRP) positive effects on the belief of participant overall health, sleep, and anxiety. Qualitative analysis during the study found selfreported improvements in the categories of stress management, relaxation, pain management, and overall general benefit [7].

Donnely et al. [8] also measured the significance of incorporating an 8-week yoga program into the rehabilitation of TBI patients. Thirty-one patients completed pre- and postprogram QOLIBRI questionnaires and the overall QOLIBRI scores had statistical improvement from $1.93(\mathrm{SD}=0.27)$ to 2.15 (SD = $0.34, p=0.01) 8$. There was also an increase in the Emotions and Feeling subscales of the QOLIBRI measurement from 1.69 (SD $=0.40)$ to $2.01(\mathrm{SD}=0.52, \mathrm{p}=0.01)$ and $2.1(\mathrm{SD}=0.34)$ to 2.42 ( $S D=0.39, p=0.01$ ) respectively [8]. Similar to Silverthorne et al. [3], Wen et al. [9] chose to examine how the addition of yoga into rehabilitative programs could possibly be beneficial for both the physical and mental ailments of patients with TBI. Two participants were entered into the study and the quantitative measurement tools were used for the study were the Pittsburgh Sleep Quality Index, Neuropathy Pain Scale, and the Behavior Rating Inventory of Executive Function (BRIEF) with evaluation taking place pre-, during, and post-intervention [9]. One patient had a $25 \%$ reduction in depression symptoms post-intervention and a $12.5-25 \%$ improvement in the Inhibition and Emotional Control scales of the BRIEF measurement tool [9]. Qualitative measurements were also promising with reported reduction in pain and decreased difficulty with sleep [9].

Schmid et al. [10] used quantitative and qualitative data to evaluate the clinical significance of adding an 8-week $1: 1$ yoga program to the rehabilitation program of patients suffering from TBI. There were measurable improvements among all participants with group balance increasing by $36 \%$, 
lower extremity strength increasing by $100 \%$, and endurance increasing by $105 \%$ [10]. Qualitative data was positive from all participants and supported the utilization of yoga to improve physical functioning among TBI patients [10].

\section{Discussion}

The studies used for this mini review show positive results with the integration of yoga into the rehabilitation programs of patients suffering from chronic traumatic brain injuries. There are difficulties when discerning the true impact of using yoga in these programs due to the diversity of the studies. Only two of the studies included in this review had both experiment and control groups used for intervention comparison $[3,8]$. There were also multiple measurement tools used for the studies with only two studies utilizing the same measurement tool for comparison (QOLIBRI) [6,8]. All studies had relatively low sample sizes with the largest sample size being $n=318$. In all studies, both quantitative and qualitative data supported the hypothesis that yoga integration into a TBI rehab program would be beneficial. In both studies with control groups, the experimental group had statistically significant positive results when compared with the control group $[3,8]$. All studies had qualitative data which was found to be positive and showed that participants both enjoyed and felt that they benefited from the yoga intervention. It is likely that given the cost benefits and the current positive research regarding yoga intervention more research will be done to incorporate this type of program into the rehabilitation of patients suffering from traumatic brain injuries.

\section{Conclusion}

The findings suggest that utilizing yoga in the rehabilitation programs of TBI patients is beneficial. The results are encouraging, and hopefully future research will be conducted in an effort to improve the overall health and outcomes of patients suffering from TBI. Larger sample sizes and multi-facility research would be beneficial to decrease the current study limitations.

\section{References}

1. Dewan MC, Rattani A, Gupta S, Baticulon RE, Hung Y C et al. (2019) Estimating the global incidence of traumatic brain injury. Journal of Neurosurgery 130(4): 1039-1408.

2. Traumatic brain injury \& concussion. Centers for Disease Control and Prevention (2019).

3. Silverthorne C, Khalsa SB, Gueth R, DeAvilla N, Pansini J (2012) Respiratory, physical, and psychological benefits of breath-focused yoga for adults with severe traumatic brain injury (TBI): A brief pilot study report. International Journal of Yoga Therapy (22): 47-52.

4. Baker MS (2014) Casualties of the global war on terror and their future impact on health care and society: A looming public health crisis. Military Medicine 179(4): 348-355.

5. Cooney MT, Carroll Á (2016) Cost effectiveness of inpatient rehabilitation in patients with brain injury. Clinical Medicine 16(2): 109-113.

6. Montgomery L, Schmid AA, Davis, TL, Jenna E Mitchell, Elizabeth R et al. (2015) Changes in emotional regulation and quality of life after therapeutic yoga for individuals with traumatic brain injury. American Journal of Occupational Therapy 69: 1-4

7. Combs MA, Critchfield EA, Soble JR (2018) Relax while you rehabilitate: A pilot study integrating a novel, Yoga-based mindfulness group intervention into a residential military brain injury rehabilitation program. Rehabilitation Psychology 63(2): 182-193.

8. Donnelly, KZ, Linnea, K, Grand, DA, Lichtenstein, J (2016) The feasibility and impact of a yoga pilot program on the quality-of-life of adults with acquired brain injury. Brain Injury 31(2): 208-214.

9. Wen PS, Herrin, I, Mola AL, Rodriguez, F, Maravel, B, et al. (2017) Yoga for sleep, pain, mood, and executive functioning in persons with traumatic brain injury. American Journal of Occupational Therapy 71.

10. Schmid AA, Miller KK, Van Puymbroeck M, Schalk N (2016) Feasibility and results of a case study of yoga to improve physical functioning in people with chronic traumatic brain injury. Disability and Rehabilitation 38(9): 914-920.

Your next submission with Juniper Publishers
will reach you the below assets
- Quality Editorial service
- Swift Peer Review
- Reprints availability
- E-prints Service
- Manuscript Podcast for convenient understanding
- Global attainment for your research
- Manuscript accessibility in different formats
( Pdf, E-pub, Full Text, Audio)
- Unceasing customer service
Track the below URL for one-step submission
https://juniperpublishers.com/online-submission.php

